Resumo: Pesquisamos o ensino de Geografia nas redes escolares da cidade de Catalão (GO). Analisamos procedimentos, metodologias estratégias de aulas. Os objetivos consistiram em apreender a realidade escolar e compreender como os professores de Geografia estão a ensinar seus conteúdos. A metodologia escolhida foi a de observação participante em que interagimos e convivemos com professores e alunos das Escolas pesquisadas. O encontro com a realidade escolar abasteceu e ressignificou algumas diretrizes das disciplinas de estágio supervisionado e, por fim, deu esteio ao subprojeto da Área de Geografia do Programa de Iniciação á Docência financiado pela Fundação CAPES.

\section{Looking for the teaching of Geography}

\begin{abstract}
Research the teaching of geography in school networks Catalan city (GO). Analyze procedures, methodologies strategies lessons. The objectives consisted of apprehending reality and understand how school teachers of geography are teaching their content. The methodology chosen was that of participant observation in which we live and interact with teachers and students of the schools researched. The meeting with the school reality fueled some guidelines and re-signified the disciplines of supervised internship and finally gave mainstay of the subproject area of Geography Teaching Initiation Program will funded by CAPES Foundation.
\end{abstract}

* Professor do Departamento de Geografia da Univesidade Federal de Goiás (UFG Campus Catalão). Doutor em Geografia pela Universidade Estadual Paulista Júlio de Mesquita Filho (UNESP Presidente Prudente).

\section{Palavras-chave:}

Educação básica; escolhas didáticas; $\quad$ processos pedagógicos; aprendizagem pela pesquisa.

\section{Key-Words:}

Basic education; choices didactic, pedagogical processes, learning by research 


\section{Introdução}

Durante os anos de 2010 e 2011 fizemos uma pesquisa intitulada Como se ensina Geografia em Catalão (GO)? Decidimos pesquisar, por amostragem, a forma e o conteúdo de Geografia que estava sendo ensinado na Educação Básica de Catalão - GO. Nossa pesquisa foi apoiada pela Pró-Reitoria de Graduação - PROGRAD, através do Programa de Bolsas de Licenciatura - PROLICEN - que disponibilizou uma bolsista para nos auxiliar nas pesquisas.

Como nossa pesquisa envolvia seres humanos, montamos o processo a o submetemos à apreciação do Comitê de Ética na Pesquisa da Universidade Federal de Goiás - UFG COEP/UFG que deu parecer favorável ao desenvolvimento de nossos trabalhos.

Realizados nossos objetivos de pesquisa e de posse de alguns resultados que não apontavam alternativas para a superação do estágio de desenvolvimento observado e percebido; começamos a examinar cenários possíveis para o futuro do ensino de Geografia no contexto que investigamos. Nossas prospectivas culminaram na elaboração de metas e objetivos para o subprojeto da Área de Geografia para o Programa de Bolsas de Iniciação a Docência - PIBID - que integra o Projeto Institucional da Universidade Federal de Goiás - UFG - para o biênio 2011/2013. O PIBID é um programa mantido e financiado pela Coordenação de Aperfeiçoamento de Pessoal de Nível Superior - CAPES.

Além disto, repensamos as orientações para as disciplinas de Estágio Supervisionado em Geografia que ministramos. As diretrizes para a realização dos estágios estão postas pelo Conselho Nacional de Educação - CNE -, de modo amplo; e pelo Conselho de Ensino Pesquisa e Extensão CEPE - da UFG. Não há nestas diretrizes um nó górdio e, pelo contrário, temos margens de manobra excelente. Até porque as normativas do CNE e CEPE estão muito a frente das práticas docentes mais comuns da Escola Básica. Assim que, ao efetivar as orientações na formação inicial de professores já estamos avançando. Portanto, a pesquisa nos deu fundamentos para ressaltar princípios cruciais na formação dos professores, já previstos nas recomendações do CNE e CEPE, todavia ainda não incorporadas na formação dos professores e muito distante da efetiva docência experienciada na EB.

Isto posto, inserimos neste artigo os resultados de nossas pesquisas e fazemos reflexões sobre a transformação e intervenções necessárias sobre o ensinar e o aprender Geografia nas Escolas públicas de Catalão (GO). Ratificando que o primeiro efeito foi na formação dos professores onde passamos a enfrentar as aulas fundadas na cópia e na mediação simplificada do livro didático; privilegiando a pesquisa como estratégia de ensino.

E, considerando, todavia, a situação experienciada na pesquisa, e que de modo geral se mostram tantas vezes caóticas as aulas de Geografia fizemos das nossas observações o estímulo para a reflexão sobre o que necessita ser planejado a fim de resgatar o interesse dos alunos da EB pelos conteúdos que ensinamos em nossa Disciplina. Portanto, aqui movidos em dialogar brevemente sobre a formação inicial de professores e a delinear prospectivas para questões pontuais sobre o aprender e o ensinar Geografia, dissertaremos sobre o tema delimitado.

\section{O que ensinamos?}

Temos observado aquilo que já havia sido afirmado por Ariovaldo Umbelino de

Geografia Ensino \& Pesquisa, v. 18, n.1, p. 55-66, jan./abr. 2014.

Prospectivas para o ensino de Geografia
Oliveira: os professores de Geografia da Escola Básica estão reféns de um "processo dialético de dominação"; no qual "os professores e os alunos são treinados a não pensar sobre e o que é ensinado e sim, a repetir pura e simplesmente o que é ensinado." (OLIVEIRA, 1989 p.28). Esta situação alija mestres e alunos de construírem conhecimentos. Torna-os meros cumpridores da agenda didática proposta pelo Livro Texto da Disciplina. Se vale para a Geografia, também vale para as demais disciplinas escolares. 
Mas o que se pode esperar diante de uma jornada extenuante, turmas lotadas e poucos recursos disponíveis para inventar aulas prazerosas? O resultado é que pouco se ensina e quase nada se aprende. Se o que está a acontecer nas escolas é apenas isto, então temos o caos adiante? Sim e não. O melhor é partir da premissa que o caos é agora e que temos horizontes claros e iluminados pela frente. Mas isto não é nenhuma apologia da esperança. O que pretendemos, e já estamos trabalhando neste sentido, é escolher metodologias que resultem em mais aprendizagem e menos angústia para mestres e alunos. Ensinar, como preconiza Demo (2003), através do ato da pesquisa e não da reprodução e cópia. Ensinar e aprender pela reflexão. Examinado contextos, conceitos e transpondo-os às realidades do cotidiano dos interlocutores.

Nestas ações pedagógicas descritas se insere o conceito de prospectiva. Este nos proporciona estabelecer propostas e ações que vislumbram cenários possíveis de realizar. Não se trata de fazer prognósticos ou apenas estabelecer metas para ensino e aprendizagem em contextos escolares ou da educação formal, mas de desenhar, enquanto resultado da análise de situações objetivas, uma ambiência possível de realizar eficazmente o ensino através de situações de aprendizagens significativas. Lembrando que Cavalcanti (2006) a define enquanto "resultado da construção própria de conhecimento. É a apropriação de um conteúdo de ensino pelo sujeito, o que implica na elaboração pessoal do objeto do conhecimento". (CAVALCANTI, 2006, p. 71). Mais adiante retomaremos as questões das apropriações do conhecimento, todavia, retomando o eixo que examinamos acerca da prospectiva, convém ainda afirmar que esta

permite igualmente outros processos de decisão e de condução estratégica: integrando a incerteza, a complexidade, reflexividade e distanciamento, transforma tanto as abordagens de análise quanto os modos de pensar. Dos pontos de vista social, cultural e cognitivo, a prospectiva chama a novas competências e a novos conhecimentos [...] (FOURNY \& DENIZOT, 2010, p.2)

Estes dois geógrafos franceses se debruçaram a estudar as prospectivas territoriais. As conclusões a que chegam e o desenvolvimento de sua argumentação sobre o tema são aplicaveis ao ensino de Geografia e a Educaçao de modo geral. Por este motivo estamos a trabalhar com o conceito desenvolvido no artigo citado. Assim, como se pode observar pela fala dos autores, o exame e a reflexão sobre o presente, no nosso caso o ensino local da Geografia, nos proporciona fazer exercícios de planejamento para criar um novo cenário para o processo de ensino e de aprendizagem de Geografia. Processo este que nos permite estabelecer alternativas para enfrentamento das situações de indisciplina, de desinteresse e de desatenção tão comuns nos alunos das escolas pesquisadas. Temos, certamente, uma série de disfunções que descrevem um arco em que numa extremidade temos uma formação deficiente de professores, que passa pelo desprestígio da profissão, expresso também pelos baixos salários dos professores e chega aos alunos. Estes já não se conformam com o processo escolar confinado desta escolarização nascida do modernismo e que anseia por metodologias, didáticas e estratégias que superem o quadro de giz, do livro didático e da aula plena de monotonia onde um sujeito que sabe transmite saberes aos alunos que não sabem. Mas o que não sabem? Os conteúdos selecionados pelo seu professor ou pelo editor do livro didático. Talvez as duas coisas. Por isto queremos pensar esta escola e enunciar nossas prospectivas.

Entretanto, nesta nossa trajetória, aprendemos algumas lições básicas, como por exemplo, a proposição de Arroyo (2008, p.111), onde nos ensina que "deveríamos saber mais sobre os processos mentais e intelectuais, os hábitos e valores provocados e ativados pelo como ensinamos e pelo como os educandos aprendem e se socializam". Isto significa avançar para além das questões primárias de metodologias e estratégias de ensino e aprendizagem. E nos ocuparmos das questões que envolvem as internalizações dos signos e das linguagens para nos colocarmos diante dos alunos como seu semelhantes

Geografia Ensino \& Pesquisa, v. 18, n.1, p. 55-66, jan./abr. 2014.

Bertazzo, C. J.

57 
e não ser percebidos como alienígenas. Mas como aquele que dialoga em uma perspectiva de estabelecer comunicação eficaz, pertinente e geradora de trocas, conhecimentos, percepçõese vivências. Pois conhecer, viver e estabelecer prospectivas não podem estar dissociados. Além disto, "a prospectiva supõe, sobretudo a articulação entre um saber técnico e localizado [...]. E esta articulação funda verdadeiramente o seu alcance. Quando é parcial, faz da prospectiva uma metodologia para a decisão e a ação em ordenamento [...]". (FOURNY \& DENIZOT, 2010, p.2).

Dito isto, construímos algumas estratégias, enquanto resultado desta articulação entre saberes e da reflexão que fazemos acerca do estado de arte do ensino da Geografia nas escolas pesquisadas, a fim de alançar projetos e ações pedagógicas robustas e inovadoras; partindo do pressuposto de reconcentração do foco das atenções dos alunos de modo a alcançarmos novo estágio de aprendizagem. Isto é muito mais que um simples ato de planificação de uma proposição pedagógica. Tampouco se tratade estabeler metas para o futuro fundadas na análise de estatíticas de eventos repetidos no cotidiano escolar (ou mesmo do diagnóstico primordial).

A prospectiva aporta informações e conhecimentos que nos permitem definir nossas ações estratégicas para uma intevenção escolar localizada, eficiente e eficaz. Por outras palavras, estabelece nossas possibilidades de intervir, mudar e transformar segundo uma decisão construída coletivamente em metodologias participativas. A prospectiva é uma metodologia que nos proporciona definir qual ensino e qual escola queremos. Ela é um instrumento para construir uma política escolar localizada. E, sem ufanismos, refunda nossa escola. Isto será real desde que a prospectiva seja realmente fruto do conhecimento coletivo e tenha perspectivas de valorização de todos os sujeitos da comunidade escolar. Afinando o discurso, convém deixar esclarecido que a

\begin{abstract}
atitude prospectiva não consiste em esperar a mudança para reagir, mas sim controlar a mudança no duplo sentido, em pré-atividade (preparar-se para uma mudança esperada) e em pró-atividade (provocar uma mudança desejada). Portanto, prospectiva estratégica envolve um processo de desenvolvimento de visões possíveis do futuro a partir de uma reflexão coletiva, e entende que o amanhã desejado pode ser construído.(http://www. fiepr.org.br/observatorios/FreeComponent2264content87568.shtml, Acesso em 05 de set. de 2011)
\end{abstract}

Feitas tais considerações, retomamos nosso discurso sobre a pesquisa realizada nas escolas de Catalão. Fizemos nossa pesquisa em instituições públicas, privadas e confessionais. Entrevistamos 10 professores de algumas das escolas que avaliamos, embora tenhamos acompanhado professores de 15 Escolas, atuando em cerca de 40 turmas (salas de aulas) diferentes, apenas estes 10 decidiram participar da pesquisa tendo assinado o Termo de Consentimento Livre e Esclarecido - TCLE - e respondido a nossa entrevista semiestruturada. O Quadro 1 esclarece, em detalhes, estas informações sobre os participantes da pesquisa e suas Escolas:

Quadro 1- Entrevistados por nível de ensino e tipo de Escola

Geografia Ensino \& Pesquisa, v. 18, n.1, p. 55-66, jan./abr. 2014.

Prospectivas para o ensino de Geografia

\begin{tabular}{|lccccc|}
\hline $\begin{array}{c}\mathbf{N}^{\mathbf{0}} \text { participantes por } \\
\text { categorias e níveis } \\
\text { de ensino }\end{array}$ & $\begin{array}{c}\text { Escola } \\
\text { Pública } \\
\text { Municipal }\end{array}$ & $\begin{array}{c}\text { Escola } \\
\text { Pública } \\
\text { Estadual }\end{array}$ & $\begin{array}{c}\text { Escola } \\
\text { Confessional }\end{array}$ & $\begin{array}{c}\text { Escola } \\
\text { Privada }\end{array}$ & Total \\
\hline Ensino Fundamental & 1 & 2 & 1 & 1 & 5 \\
Ensino Médio & 0 & 3 & 1 & 1 & 5 \\
\hline Total & $\mathbf{1}$ & $\mathbf{5}$ & $\mathbf{2}$ & $\mathbf{2}$ & $\mathbf{1 0}$ \\
\hline
\end{tabular}


Nos Quadros que seguem registramos as contestações destes professores às perguntas que lhes fizemos. Neste trabalho procuramos analisar apenas algumas questões que julgamos pertinentes à abordagem que fazemos do contexto que estudamos.

Quadro 2- Qual método de trabalho predominantemente utilizados em suas aulas?

\begin{tabular}{|cl|}
\hline Sujeito & Contestações à questão \\
\hline A & Aula expositiva e mediação do livro didático. Desenvolve itinerários \\
& diferentes ao livro didático. \\
B & Aula expositiva. Faz explicações sobre o conteúdo do material didático. \\
C & Verbalismo (voz e giz) e utilização de multimídia (quando necessário). \\
D & Aula expositiva com participação dos alunos; contextualização dos \\
& conteúdos; faz vinculações dos conhecimentos escolares com as informações \\
& da mídia. \\
E & Aulas expositivas. Seminários com e pelos alunos. Estimula as participações \\
& dos alunos. Escolhe aleatoriamente os alunos para apresentar suas pesquisas. \\
F & O método de trabalho predominante ainda é a exposição oral, porém um \\
& pouco enriquecido com slides, filmes e leituras complementares. \\
G & De mediação entre aluno e objeto a ser estudado, partindo sempre de \\
& questionamentos sobre o conhecimento prévio do aluno, de forma que \\
& possa construir seu próprio conhecimento. \\
H & Método crítico reflexivo. \\
I & Livro didático, aulas expositivas, resolução de atividades e demonstração de \\
& mapas variados. \\
J & Aulas expositivas, leitura de textos complementares, leitura de gráficos e \\
& mapas, atividades de fixação e estudo do livro didático.
\end{tabular}

Fonte: Pesquisa de campo, 2010-11, organizado pelo autor.

A formulação da pergunta propunha encontrar as escolhas metodológicas dos professores utilizadas nas construções dos conhecimentos geográficos em suas aulas. Observe que muitos professores são, predominantemente, verbalistas. São dialógicos, quando encontram disposições de dialogo em seus interlocutores. Alguns levam para seus alunos imagens que são mostradas através do data show. Entretanto, nem a escola privada ou a confessional durante nossa pesquisas possuíam aparelhos multimídias fixados nas salas de aulas. As públicas igualmente. Então, o professor de Geografia tem disponibilidade de usar este equipamento através de rodízio e por agendamento. Resta-nos a obrigação de concluir que a ilustração possível para as aulas de Geografia é ainda aquilo que disponibiliza o livro didático.

Há também uma tendência, embora pequena, de trabalhar com os conhecimentos espontâneos dos alunos e de valorizar os pré-requisitos que eles trazem dos estudos anteriores ou das informações que podem acessar. Estas práticas pedagógicas são importantes para que os alunos se sintam inseridos nos objetivos propostos pelos professores e pelo programa de ensino (CALLAI, 2000; PONTUSCHKA \& OLIVEIRA, 2002).

O professor em sua prática docente organiza as situações de aprendizagem que se sucedem durante a aula. É essencial que atue assim. Então, quando está dialogar com os saberes dos alunos e os compreende como uma forma diferente de produção de conhecimentos, faz com que os alunos se sintam sujeitos do processo e lhes dão motivos para interessarem-se pelos assuntos (conhecimentos) que o professor lhes descortina durantes as aulas. Esta atitude simples decorre dos planejamentos das aulas. Em cada tema o professor vai se perguntando os rumos que deve tomar para inserir aqueles conteúdos nas suas aulas. O livro didático não faz isto pelo professor. $O$ livro tem um roteiro, às

Geografia Ensino \& Pesquisa, v. 18, n.1, p. 55-66, jan./abr. 2014.

Bertazzo, C. J.

59 ISSN 2236-4994 
vezes um trilho. Ele impõe tempos e modos de ensinar e aprender. O que estamos a dizer, considerando nossas pesquisas com os professores de cujas respostas estamos a analisar, é que nas aulas em que os temas foram introduzidos aos alunos através de perguntas e exemplos que envolviam conhecimentos pré-existentes ou conhecimentos espontâneos a aprendizagem é mais efetiva. As aulas fluem melhor e os alunos se interessam pelo tema, passando a formular perguntas. Porém não acontece em todas as aulas.

Também se observa que os professores ao estimularem o interesse dos alunos buscando situar o objeto de estudo próximo do seu cotidiano, definindo claramente os objetivos de suas aulas, na verdade eles estão criando um contexto de aprendizagem que facilita a construção do conhecimento por parte dos alunos (MORETTO, 2007). Estas atitudes corriqueiras e simples, incorporada aos procedimentos metodológicos dos professores (às vezes externalizadas como técnicas de aulas) também produz o empoderamento de seus alunos. Faz com que se sintam sujeitos e não objetos das aulas. Com isto, os alunos se sentem capazes de pensar e refletir nos conteúdos e conceitos que lhes são propostos e conseguem apropriar-se dos conhecimentos mediados pelo professor. Isto não se realiza sempre, mas não é casuístico. Pois em algumas observações se percebia que os alunos estavam confortáveis com tais procedimentos.

O esforço dos docentes, que se percebe nas respostas, é notável. Todavia eles têm seu foco no ensino, na quantidade de conteúdos e na sequência do livro didático. Esta é a tarefa primordial da docência: ensinar. Mas disto emerge o principal problema da docência: o aprendizado dos alunos (BORDENAVE \& PEREIRA, 1991). Precisamos todos nos preocupar como e se os alunos aprendem.

Lacoste (1989) reclamou que a Geografia escolar - "dos professores" apoiava-se basicamente nas habilidades de memória, logo não precisava ser compreendida/entendida/ aprendida, mas apenas decorada/memorizada para atender as demandas apresentadas pelos docentes e poder lograr aprovação em exames e provas escolares. O lamentável é que ainda fazemos um pouco (ou um muito) disto. Se esta é nossa prática, então precisamos agir no sentido de acompanhar a efetiva aprendizagem dos alunos. Não mais a memória efêmera, e só necessária ao ritual de aprovação, que não é uma aprendizagem de fato, mas uma situação transitória. Focar nossa prática docente na aprendizagem dos alunos é um passo importante para aperfeiçoar nossa docência e a formação de professores. Neste sentido, o melhor instrumento para acompanharmos o processo de aprendizagem de nossos alunos, sempre será uma eficaz avaliação. Esta, todavia, sendo compreendida "como um momento privilegiado de estudo e não um acerto de contas" (MORETTO, 2007, p.29)

Antes de encerrar os comentários sobre o Quadro 2, desejamos destacar a postura do sujeito D, cujas estratégias de contextualizar os conteúdos de Geografia com o cotidiano dos alunos e fazer a vinculação entre a Geografia das mídias com os conteúdos de sala de aula; visivelmente marcham no sentido de enfrentar uma situação de precarização da Geografia na Escola: "De todas as disciplinas ensinadas na escola, no secundário, a [G] eografia é a única a parecer um saber sem aplicação prática fora do sistema de ensino“ (LACOSTE, 1989, p.15). Quer dizer, a crítica de Lacoste a um modelo de ensino em França e a prática dos docentes de sua época (ou do tempo em que escreveu) não abrange a totalidade dos professores de Geografia em todos os lugares e em todos os tempos. Nosso

Geografia Ensino \& Pesquisa, v. 18, n.1, p. 55-66, jan./abr. 2014

Prospectivas para o ensino de Geografia professor - sujeito D - desconstrói esta tese. Na verdade, depois que estas águas passaram sobre a ponte, temos aprendido a relacionar a Geografia com o cotidiano. Embora este seja uma realidade presente nas práticas dos professores de Geografia, pois segundo diagnostica Kaercher (2007, p.5) em sua pesquisa doutoral "falta relacionar escola e vida, a fim de que o aluno perceba o vínculo dos assuntos trabalhados com sua vida extra-escolar". Todavia, estamos avançando deste estágio. Mas o que fazer com os professores que estão na ativa? Formação continuada. Enquanto isto, ressignificamos a formação de professores. 
Prossigamos, agora, com as escolhas metodológicas dos professores.

Quadro 3- Utiliza técnicas variadas em sua metodologia de trabalho: Quais?

\begin{tabular}{|c|c|}
\hline Sujeito & Contestações à questão \\
\hline A & $\begin{array}{l}\text { Sim, Utiliza sala de informática e internet; fixa mapa nas turmas do } 6^{\circ} \text {, } \\
7^{\circ}, 8^{\circ} \mathrm{e} 9^{\circ} \text {. }\end{array}$ \\
\hline B & $\begin{array}{l}\text { Data Show (sim) Utiliza conexões da internet faz pesquisa e projetos } \\
\text { pela multimídia para realizar na aula. Usa muito o programa Google } \\
\text { earth. }\end{array}$ \\
\hline $\mathrm{C}$ & Sim, filmografia; debates; provoca as participações. \\
\hline $\mathrm{D}$ & Data Show; vídeos. Conquistar a confiança dos alunos. \\
\hline $\mathrm{E}$ & Usa data show, uso da pesquisa para ensinar conceitos e conteúdos. \\
\hline $\mathrm{F}$ & $\begin{array}{l}\text { Às vezes. Já foi citado acima, e, além disso, a utilização de filmes é uma } \\
\text { constante. }\end{array}$ \\
\hline G & $\begin{array}{l}\text { Na medida do possível. Aulas expositivas, leituras de jornais e revistas } \\
\text { (atualidades), filmes, slides, análise, interpretação, e confecção de mapas. }\end{array}$ \\
\hline $\mathrm{H}$ & $\begin{array}{l}\text { Sim, aulas expositivas, resumo, sínteses, produção de textos, cartazes, } \\
\text { seminários (slides e vídeos), pesquisas em jornais, livros e internet. }\end{array}$ \\
\hline I & $\begin{array}{l}\text { Uma vez por semestre, devido a dificuldades, visitas o DIMIC e } \\
\text { amostra de filmes. }\end{array}$ \\
\hline $\mathrm{J}$ & $\begin{array}{l}\text { Sim. Vídeos, elaboração de cartazes com recortes de figuras e } \\
\text { reportagens, pesquisas. }\end{array}$ \\
\hline
\end{tabular}

Fonte: Pesquisa de campo, 2010-11, organizado pelo autor.

As respostas clarificam o estado de domínio tecnológico e as mídias que nossos mestres utilizam para ministrar conteúdos geográficos em suas aulas. Elas expressam as auto avaliações dos professores sobre suas próprias práticas. Podem até estar superestimadas, e não nos cabe opinar sobre elas, entretanto, nem todos disponibilizam abundantemente das mídias ou não conseguem planejar suas aulas para (e com) o uso de tais equipamentos.

O sujeito F declarou que usa pouco as mídias. Entretanto, o sujeito B usa o programa Google earth em linha em suas aulas. Dois parâmetros. Consideramos que apenas utilizar os equipamentos e mídias como suporte para as aulas pode representar modernidade e domínio das novas tecnologias a favor da educação. E são muito importantes. Contudo, os objetivos da aula não se realizam automaticamente. A mediação do professor é fundamental. Ele precisa agir de modo que sua proposta de aula aconteça com eficácia. Embora isto não dependa apenas dele, sua atuação é fundamental para que a aula siga os objetivos enunciados (PERRENAUD, 2000). Então, que o professor use equipamentos para ministrar os conteúdos de Geografia, quer use apenas o livro didático em sua ministração, sua percepção deve estar bem aguçada para compreender o sentido que sua aula toma. Se a evolução dos acontecimentos em aula não descolam a aula real do planejamento. Isto pode acontecer que use mídias ou se trate de uma aula expositiva, fundada ou não no diálogo com os alunos e recheada, ou não de oportunidades de participação dos alunos no fluxo do plano de aula.

Desse modo, é importante que todo planejamento esteja engajado em metodologias participativas; nas quais todos se tornem sujeitos dos saberes estudados e reelaborados. Isto pode acontecer ainda que as estratégias do professor não sejam muito diversificadas. Todavia é preciso trabalhar com um olho no planejamento e o outro nas respostas dos alunos. Por outras, palavras, muito além de diversificar as metodologias das aulas, e de usar, ou não, as mídias para desenvolver os conteúdos, necessita o professor avaliar o conhecimento que está sendo produzido através de sua mediação.

Por que esta necessidade? Ela tem um sentido profundamente humanista e solidário: se

Geografia Ensino \& Pesquisa, v. 18, n.1, p. 55-66, jan./abr. 2014.

Bertazzo, C. J.

61 ISSN 2236-4994 
trabalhamos fundados no desejo da subjetivação dos nossos alunos, não podemos torná-los meros reprodutores e copistas dos conhecimentos acadêmicos. Pelo contrário, devemos proporcionar (planejando-as) situações de aprendizagem em que nossos alunos de Geografia usem suas capacidades intelectuais para refletir, deduzir, contestar, sintetizar, concluir e etc.

Então por que perguntamos sobre as metodologias que os professores empregam em suas estratégias de ensino? Bem, as metodologias são instrumentos para se alcançar os objetivos maiores que se fundam na elaboração, construção, reelaboração e reconstrução de saberes (DEMO, 2003). São as metodologias que determinam que o professor e seus alunos os alcancem. São as atitudes e procedimentos do professor e de seus alunos que definem se haverá construção de saberes na sala de aula ou se os alunos apenas usarão a memória temporária para desincumbirem-se das atividades relativas aos conteúdos de Geografia. Por isso enfatizamos mais os objetivos da aula. Como, em tese, os objetivos das aulas de qualquer professor expressa-se na aprendizagem efetiva e não uma simples colagem efêmera dos conteúdos que se estuda. A preocupação maior é, ou deveria ser, a aquisição do saber, não como resultado da transmissão, mas pela elaboração própria de cada sujeito educacional. Assim, a metodologia faz sentido quando está em sintonia fina com os objetivos da aula e da educação libertadora, que, em última análise, concebe um cidadão-aluno capaz de pensar com autonomia e total liberdade.

Antes de finalizar, vamos resgatar a resposta do sujeito I: foi o único que utiliza visitas a campo enquanto técnica de ensino. As observações do meio sempre foram tão caras a Geografia e na realidade destes professores ficou ausente. Sabemos que é trabalhoso retirar os alunos de dentro da escola, porém, no campo, se aprende bastante. Logo, um pouco de trabalho fica compensado quando o professor observa apropriação de saberes que uma visita técnica proporciona.

Por último, queremos comentar o protagonismo do sujeito E que se serve da pesquisa como método para seus alunos aprenderem conceitos e conteúdos de Geografia. Tal entrevistado não indicou quanto e em que ocasiões lança mão desta estratégia de ensino, todavia é muito significativo que a tenha inserido. Aqui está uma alternativa importante para a mudança e para a supressão da cópia na EB e capaz de retirar a Geografia do rol das disciplinas que só exigem memória daqueles que as estudam. Assim, considerando o tema como parte das estratégias de aprendizagem, inquirimos dos professores se ministravam tarefas para seus alunos realizarem em casa. Vamos ao registro das respostas.

Quadro 4- Os alunos realizam tarefas fora da sala de aula: Quais?

\section{Sujeito Contestações à questão}

A Dificilmente apenas pesquisas e trabalhos que, invariavelmente são copiados.

B Sim, Respondem as atividades- tarefas- que estão no material didático da escola ( universitário) Eventualmente solicita pesquisa para aprofundar temas de trabalhar em aula

C Sim, oficinas (gastronômica), pesquisas, atividades da apostila do curso.

D Sim, as tarefas propostas pela professora.

E Pesquisar para realizações de seminários. Atividades propostas pelo livro didático e

dos temas relacionados e acrescentados pela professora

Geografia Ensino \& Pesquisa, v. 18, n.1, p. 55-66, jan./abr. 2014.

F Às vezes. Atividades de leitura e escrita, respondendo questões concernentes a matéria explicada.

G Não, noturno.

$\mathrm{H}$ Às vezes. Atividades escritas (questões, produção de texto, cartazes) e trabalhos de campo, produção de slides e vídeos.

I Pesquisas e palestras em diferentes lugares, como no SENAC e na UFG.

J Sim. Cinema, bibliotecas, visitas ao IBAMA,UFG e outros 
Nossos entrevistados não utilizam, sistematicamente, estas estratégias metodológicas. Todos os docentes as utilizam de forma eventual. É uma alternativa casual, ela não consta do planejamento, surge até mesmo como demanda dos discentes. Não inquirimos as razões que os levam a utilizá-las, ou não. Não perguntamos pelas tarefas em si, mas o como elas são encaminhadas e a valorização que os esforços dos alunos empreendem nelas. Isto sim é significativo e reveste a atividade de um sentido especial de evoluir e trabalhar conceitos, pesquisar, fazer leituras dirigidas, etc. O importante é que os planos de curso dos professores pudessem prever tais atividades extraclasses.

Quanto aos pressupostos defendidos para a formação de professores e ao ensino da Geografia na Educação Básica, vemos que é uma necessidade fundamental inserir o ensino de Geografia através de estratégias que tem se mostrado eficientes, como o lúdico, o teatro e os jogos didáticos. Assim, os docentes tem que experimentar estas situações na academia. É necessário vivenciar nos laboratórios em que são formados como docente a fim de que conheçam as possibilidades destas ferramentas em situações reais de ensino. Não basta informar o aluno em estágio de formação inicial de professor sobre tais possibilidades. Os formadores são os protagonistas para que os acadêmicos compreendam os processos e oportunidades em que tais estratégias são/serão utilizáveis. Portanto, estas foram as conclusões que nos levaram a redirecionar nossas práticas de formador de docentes de Geografia. $\mathrm{O}$ aluno necessita experienciar outras formas de ministrar aulas de Geografia, que não se limitem as aulas expositivas apoiadas (ou não) pelos livros didáticos e apostilas governamentais.

Retomando a questão central analisada no Quadro 4, dizemos que as proposições de tarefas que viabilizem diálogos e investigações com a realidade vivida pelos alunos colaboram com a construção autônoma do conhecimento e fortalecem a formação cidadã. Sabemos, por conseguinte, que o planejamento de tarefas extraclasses demanda reflexionar sobre a realidade, pensar em conteúdos e direcionar o foco dos alunos para as questões geográficas que estão tão fortemente presentes em seus cotidianos. No fim de tudo, o mais comum, mais simples e menos trabalhoso é solicitar que os alunos respondam as perguntas do livro didático em seus cadernos, como tarefa para casa. $\mathrm{Na}$ aula seguinte eles apresentam os resultados aos professores e recebem ponto para a avaliação do trimestre.

Enfim, para que elaborar tarefas extraclasses se elas resultarão em mais trabalho aos docentes? Bem, quando alguém se decide pela Licenciatura em Geografia precisa ter a clareza de que o trabalho docente é pleno de atividades e o labor não é pequeno. A prática docente tem destas coisas: ensinar e educar, e movimentar os alunos para fora de suas zonas de conforto, ou da inércia posicional. Então isto nos inclina a refazer a pergunta acerca do estado de arte da formação de professores: por acaso, não estaria a formação dos professores, presentemente, a reboque das coisas que estão em processo na escola? Os legisladores não param de inserir mudanças na Educação Básica. Todavia não interferem tanto na formação de professores, isto é primazia do Ministério da Educação.

Assim, na academia formam-se professores para educar e ensinar, embora possam gerar alienados à realidade dos alunos e da escola real. Primordialmente, como nos lembra Guerrero (2006), a academia promove a inserção dos alunos no mundo da Educação e da formação dos sujeitos e cidadãos, de modo que a formação docente é uma das principais bases para a realização de mudanças na
educação formal. Por meio de conhecimentos de teorias oriundas do campo de
pesquisa da Psicologia da Educação e da Didática, que são capazes de subsidiar a
organização de objetivos pedagógicos, a seleção de materiais adequados e a elaboração
de procedimentos e sequências didáticas, professores implementam mudanças na
aprendizagem dos alunos. (GUERRERO, 2006, p. 113-14)
Geografia Ensino \& Pesquisa, v. 18, n.1, p. 55-66, jan./abr. 2014.

Bertazzo, C. J.

Já estamos atrasados no ajuste que devemos fazer entre a formação inicial de professores 
para os ajustes que estão acontecendo nas escolas. Se nossos alunos adquirirem as habilidades e competência de que fala a autora, ainda assim teremos mais solicitações e demandas escolares, originadas na, comunidade, no governo, na administração da escola, dos pais, dentre outros demandantes. Cada vez mais a escola exige de seus professores coisas que ultrapassam em muito o as tarefas de cunho pedagógico estrito. Este não pode nunca ter seu valor diminuído. Pelo contrário, é a base de toda a ação docente.

Finalmente, não deixaremos escapar nossa leitura sobre a formação docente: A academia forma professores para a escola real, embora atue em descompasso com a realidade que está em curso na vida escolar. Nossa pesquisa nos orientou para encontrar o movimento e a velocidade com que as coisas acontecem na escola e reorientar a formação inicial dos professores. Estamos aprendendo a fazer as coisas. Adensamos o tempo de permanência dos alunos nas escolas para que possam, neste ir e vir, pensar e problematizar as realidades que percebem e estabelecer diálogos entre academia, teorias, contextos escolares e sua formação e instrumentalização para o exercício da profissão e das escolhas metodológicas que necessitam (rão) fazer.

\section{Considerações finais}

Posta estas considerações, que resta a propor ao Ensino da Geografia, que ainda não tenha sido feito e que não seja uma escolha metodológica experienciada por mestres em suas práticas docentes? $\mathrm{Na}$ verdade não precisamos de estratégias inovadoras, apenas renovar as nossas metodologias e também de nos redescobrirmos em nossas nobres funções de ensinar com eficácia, não só como tarefeiros, porém, como aqueles que alcançam seus objetivos através da aprendizagem dos discentes.

Reflexionando em tudo isto, e pensando, sobretudo na eficácia do ato de ensinar, cujas raízes se assentam nas relações entre os alunos e a Ciência Geográfica, as quais dependem sobremaneira da mediação didática do professor de Geografia e de sua maneira de ensinar; construímos uma prospectiva para o ensino da Geografia que entendemos fundamentais para criar uma relação duradoura entre os educando e a Geografia, que passamos a relacionar e a descrever a seguir:

a) Em primeiro lugar, reconhecemos a preponderância do desenvolvimento de metodologias alternativas para o ensino-aprendizagem de Geografia que superem a mediação do livro didático. Então se torna, por exemplo, promover o uso dos recursos lúdicos para a construção de saberes e para a compreensão dos conceitos conteúdos de Geografia. Os jogos didáticos e outras formas lúdicas tem se consolidado como ferramentas de autoaprendizagem e autodesenvolvimento que muito contribuem para a aprendizagem dos discentes, desde que sejam atividades planejadas e orientadas para a apreensão de conteúdos geográficos.

b) Em segundo lugar, é necessária a preparação e organização de atividades práticas vinculadas aos conceitos geográficos que permitam incorporação dos saberes e dos conceitos estudados. Está patente nas relações entre professores-alunos-conhecimento que, apenas as formas de aulas expositivas, não são capazes de desenvolver as habilidades e competências dos discentes. A aprendizagem é dependente do fazer, do praticar. Apenas ouvir e ler não gera conhecimento: precisamos de ações que resultem em experiências. Precisamos vivenciar as

Geografia Ensino \& Pesquisa, v. 18, n.1, p. 55-66, jan./abr. 2014

Prospectivas para o ensino de Geografia teorias, quer dizer devemos promover o aprender pelo fazer. Praticar e aprender. Neste caso, as pesquisas são princípios fundamentas para a aprendizagem (DEMO, 2006).

Finalmente, ações pontuais de formação continuada podem estimular e motivar os professores da Escola Básica a produzirem materiais de apoio. Isto promoverá atividades didáticas diversificadas que venham ao encontro do agir pedagógico planejado, sob o âmbito de uma resgatada soberania pedagógica. Quer dizer o professor voltar a ser o autor das situações de ensino e da construção de seus materiais de ensino. 
A partir deste estágio os professores desenvolveriam suas estratégias de ensino ancoradas nos materiais de apoio que criaram, reelaboraram ou adaptaram. O imprescindível é iniciar a caminhada de autonomização do professorado e lhes permitir, e garantir, que sejam autores de suas intervenções docentes. E isto afirmamos em um cenário que cada vez mais as Secretarias de Educação estão a criar pacotes didáticos sufocantes e autoritários para os professores da Escola Básica executar. Apesar disto é possível inventar, inovar e resilir.

\section{Referências}

ARROYO, Miguel G. Ofício de mestre: imagens e auto-imagens. 10 ed. Petrópolis: Vozes, 2008.

BORDENAVE, Juan Maria; PEREIRA, Adair Martins. Estratégias de ensino-aprendizagem. Petrópolis: 12 ed. Vozes, 1991.

CALLAI, Helena; CASTROGIOVANNI, Antônio C.; KAERCHER, Nestor. Ensino de Geografia: práticas e contextualizações do cotidiano. Porto Alegre: Mediação, 2000.

CAVALCANTI, Lana de Souza. Ensino de Geografia e diversidade: construção de conhecimentos geográficos escolares e atribuição de significados pelos diversos sujeitos do processo de ensino. In: CASTELLAR, Sonia. Educação geográfica: teorias e práticas docentes. São Paulo: Contexto, 2006.

GUERRERO, Ana Lúcia de Araújo. Contribuições da teoria da atividade para a formação continuada de professores de Geografia. In: CASTELLAR, Sonia. Educação geográfica: teorias e práticas docentes. São Paulo: Contexto, 2006.

FOURNY, Marie-Christine; DENIZOT, Damien. A prospectiva local, um modo de produção e governança, Confins [Online], 9 | 2010, posto online em 22 jul. 2010, Disponível em: http://confins. revues.org/6502. . DOI : 10.4000/confins.6502. Acesso em 5 set. 2011.

KAERCHER, Nestor A. Quando a Geografia Crítica é um pastel de vento e nós, seus professores, Midas. In: Anais... COLOQUIO INTERNACIONAL DE GEOCRÍTICA, 9. 2007. Porto Alegre.

LACOSTE, Yves. Geografia isso serve, em primeiro lugar, para fazer a guerra. 2. ed. Campinas: Papirus, 1989.

Metodologia: Prospectiva Estratégica. Disponível em: http://www.fiepr.org.br/observatorios/ FreeComponent2264content87568.shtml;acesso em 05 de set. de 2011.

MORETTO, Vasco Pedro. Prova um momento privilegiado de estudo - não um acerto de contas. 7 ed. Rio de Janeiro, DP\&A, 2007.

Geografia Ensino \& Pesquisa, v. 18, n.1, p. 55-66, jan./abr. 2014.

Bertazzo, C. J.
65 |

ISSN 2236-4994 
PONTUSCHKA, Nídia Nacib; OLIVEIRA, Ariovaldo Umbelino de. (orgs). Geografia em perspectiva. São Paulo: Contexto, 2002.

\section{Correspondência:}

\section{Claudio Jose Bertazzo}

E-mail: cbertazzo@gmail.com

Recebido em 16 de maio de 2013.

Revisado pelo autor em 05 de setembro de 2013.

Aceito para publicação em 04 de fevereiro de 2014.

Geografia Ensino \& Pesquisa, v. 18, n.1, p. 55-66, jan./abr. 2014

Prospectivas para o ensino de Geografia 